Title: Development and randomised controlled trial of a Continence Product Patient Decision Aid for men post-radical prostatectomy

Running Title: Continence Product Patient Decision Aid

Authors:

Catherine Murphy ${ }^{1}$

Christine de Laine ${ }^{1}$

Margaret Macaulay ${ }^{1}$

Mandy Fader ${ }^{1}$

Institution:

${ }^{1}$ School of Health Sciences, University of Southampton

Corresponding author's details:

c.murphy@soton.ac.uk

+44 2381206552

Conflict of Interest Statement:

No conflicts of interest to declare

Funding statement:

This work was funded by the Movember Foundation in partnership with Prostate Cancer UK as part of True NTH programme.

This article has been accepted for publication and undergone full peer review but has not been through the copyediting, typesetting, pagination and proofreading process, which may lead to differences between this version and the Version of Record. Please cite this article as doi: 10.1111/JOCN.15223

This article is protected by copyright. All rights reserved 
DR. CATHERINE MURPHY (Orcid ID : 0000-0003-1244-5106)

Article type : Original Article

\section{Development and randomised controlled trial of a Continence Product Patient Decision Aid for men post-radical prostatectomy}

\section{Abstract}

Aims and Objectives: to develop and evaluate an evidence-based Continence Product Patient Decision Aid (CP-PDA) to reduce decisional conflict and support continence product choice for men post-radical prostatectomy.

Background: In 2018, 1.3 million men globally were diagnosed with prostate cancer. A common treatment is radical prostatectomy, usually leading to sudden-onset of urinary incontinence. For people experiencing incontinence, products to contain leakage are fundamental to health-related quality-of-life, but many product users and healthcare professionals are unaware of available options. No evidence-based guidance on choosing products exists despite known physical and psychological burdens of poorly managed leakage (e.g. isolation, anxiety, depression, skin-damage).

Design and Methods: 4 phases, underpinned by international decision-aid guidance.

I. Evidence/expert opinion: Literature review; consultation with specialist continence clinicians $(n=7)$ to establish evidence-base.

II. Prototype: CP-PDA developed with continence specialist $(n=7)$ feedback.

III. Alpha testing (stakeholders): CP-PDA materials were provided to expert patients $(n=10)$ and clinicians $(n=11)$ to assess content/presentation.

IV. Beta testing (field) following CONSORT guidelines, registered NIHR CPMS 31077: men ( $\mathrm{n}=50)$ post-radical prostatectomy randomised to evaluate usability and decision-making using the Decisional Conflict Scale compared with usual care.

This article is protected by copyright. All rights reserved 
Results: An algorithm differentiating patients by mobility, dependency, cognitive impairment and type/level of leakage, leading to 12 user groups was developed. For each group, an option table and associated product information sheets guide product choice. Total Decisional Conflict Score for men using the CP-PDA was significantly better than for men without. CP-PDA users reported greater confidence in product knowledge and choice.

Conclusion: This is the first evidence-based CP-PDA, developed using an internationally recognised method. Compared to usual care, it significantly reduced decisional conflict for men choosing continence products post-prostatectomy.

Relevance to clinical Practice: The CP-PDA provides nurses with the first comprehensive, evidencebased intervention to help post-prostatectomy men in complex continence product choices. An online version is available: www.continenceproductadvisor.org.

Key Words: Prostate cancer, Incontinence, Continence Products, Absorbent Pads, Decision-making, Quality-of-Life, Patient Decision Aid

This article is protected by copyright. All rights reserved 


\section{INTRODUCTION}

The majority of men who undergo radical prostatectomy as a treatment for prostate cancer will experience at least transitory urinary incontinence, often lasting for many months (Daugherty, Chelluri, Bratslavsky, \& Byler, 2017, Haglind et al., 2015). For these men, using the most appropriate continence products to adequately contain urinary leakage is fundamental to health-related qualityof-life (Hislop Lennie, Clancy, Westbury, Okamoto, \& Fader, 2018). However, most of these men do not have previous experience of managing leakage, with many reporting a lack of knowledge on the available range of continence product designs and an absence of support in choosing the best options to meet their needs (Macaulay, Hislop Lennie, Clark O’Neill, \& Fader, 2018). No evidencebased guidance on choosing products exists despite known physical and psychological burdens of poorly managed leakage. This paper describes the development and trial of an evidence-based Continence Product Patient Decision Aid (CP- PDA) to reduce decisional conflict and support continence product choice for men post radical prostatectomy.

\section{BACKGROUND}

Prostate cancer is the fourth most common cancer in the world. The number of men living with this disease is increasing, with around 1.3 million men diagnosed in 2018 (World Cancer Research Fund, 2019). Many men will undergo radical prostatectomy, with almost 1 million men in the United States alone undergoing the procedure between 1998 and 2011 (Tyson et al., 2016). A common side effect of surgery is the sudden onset of urinary incontinence (Daugherty, Chelluri, Bratslavsky, \& Byler, 2017, Haglind et al., 2015) and, when this happens, adequate containment of leakage is fundamental to health and quality of life. Urinary incontinence can have a profoundly negative effect on men's quality of life, including increasing the risk of anxiety or depression (Kohler et al., 2014) or decisional regret on choice of treatment (Albkri et al., 2018). Poorly contained leakage causes considerable harm, for example increasing social isolation (Braaf, Lennox, Nunn, \& Gabbe, 2017, Keighley, Perston, Bradshaw, Hayes, \& Keighley 2016), burden on carers (Santini, Andersson, \& Lamura, 2015), risk of falls (Noguchi et al., 2016), likelihood of care home admission (Morrison \& Levy, 2006) and damage to skin (Beeckman 2016).

Fundamental to effective containment is the right product to meet individual needs, taking into account type of leakage, varying physical or cognitive factors, daily activities and personal values. Not all designs will be suitable immediately post-prostatectomy and all products have benefits and disadvantages for varying circumstances, activities and personal preferences. For example, a

This article is protected by copyright. All rights reserved 
washable diaper style product can be popular with men with heavy night-time leakage (Fader et al., 2008), but is only a good choice if the individual can tolerate the bulk and aesthetic and has the facilities to wash and dry the products. Additionally, a range of products may be required to best meet individual needs; for example, men could prefer absorbent pads at night but a mixture of pads and devices for day-time use (Macaulay et al., 2015). And the question remains: 'How does one choose?' Although manufacturers provide marketing information, it is limited to their own brand with no comparisons of other products. To make informed decisions, both users of products and their healthcare providers require evidence-based product information.

Research literature and clinical guidance on managing post-prostatectomy incontinence focuses on conservative (e.g. pelvic floor muscle training) and surgical (e.g. urethral slings) approaches. There is no evidence-based guidance on managing leakage with continence products despite this being the initial management strategy post urinary catheter removal (when urinary control varies between men from full continence to no urinary control). Continence products will additionally be the longterm choice for many men for whom conservative or surgical incontinence treatments do not work or are not appropriate.

Absorbent pads (both disposable and washable) and body worn devices specifically for men (such as urinary sheaths or penile compression devices) are available (Cottenden et al., 2017) but men can find the options overwhelming (Hislop Lennie, Clancy, Westbury, Okamoto, \& Fader, 2018). Men are 'novices in the pad department' (Macaulay et al. 2018) and may struggle to navigate their way through the many options. Many people do not access or will delay seeking professional help to treat or manage leakage (Grzybowska, Wydra, \& Smutek,. 2015). Less effective self-management, including choice and purchase of ill-fitting containment products, is common and can lead to a negative impact on quality of life and relationships (Hislop Lennie, Clancy, Westbury, Okamoto, \& Fader, 2018). Most men in this population are not experienced in choosing continence products and can find the process confusing and distressing. They feel unsupported and lacking in knowledge to make product choices to manage their incontinence (Macaulay, Hislop Lennie, Clark O'Neill, \& Fader, 2018). Previous research has reported that insufficient attention is "paid to the balance between the beneficial and negative treatment effects of absorbent pads" and that products can have a complex influence on quality-of-life necessitating "careful selection of the most appropriate pad for each individual to minimize unfavourable side effects" (Getliffe, Fader, Cottenden, Jamieson, \& Green 2007).

This article is protected by copyright. All rights reserved 
In 2016 - and as part of the 6th International Consultation on Incontinence - an international group of academic and clinical experts reviewed the existing research evidence on managing incontinence using continence products. Their aim was to produce evidence-based guidelines for different user groups and clinicians wanting to select appropriate products and use them effectively (Cottenden et al., 2017). Following discussion of their preliminary findings with a wider international group of experts at the consultation conference (6th International Consultation on Incontinence, Tokyo 2016) they concluded that having an evidence-based decision aid for men was a research priority (Cottenden et al., 2017).

Patient decision aids are designed to provide high quality information, helping people to choose between potential treatment or care options. They combine clinical information (including the advantages and disadvantages of options) with their own preferences and values. A Cochrane review of 105 studies of patient decision aids (pamphlets, videos or web-based tools) concluded that an aid can significantly improve knowledge and lead to a higher proportion of people selecting options congruent with their values (Stacey et al., 2017). There is growing recognition of the need to support people living with the long-term effects of cancer treatment via policy and practice development (Foster, Calman, Richardson, Pimperton, \& Nash, 2018). Despite this, the search revealed no patient decision aid was available for the complex and important field of continence product choice.

With this in mind, our aim was to systematically develop and evaluate a Continence Product Patient Decision Aid (CP-PDA) for men with urinary incontinence post-prostatectomy. We hypothesised that a CP-PDA would increase self-perceived product knowledge and reduce conflict about the choices they make. Decisional conflicts were assessed using the Decisional Conflict Scale, a validated tool to measure healthcare consumers' decisional uncertainty (O'Connor, 1995).

\section{Methods}

\section{Design}

Comprising four stages, this study followed the International Patient Decision Aids Standards Criteria Checklist (Elwyn et al., 2006). Developing a Patient Decision Aid is a multi-step process, including initial alpha-testing with stakeholders (e.g. experienced patients), followed by beta-testing in the field. An NHS Research Ethics Committee provided ethical approval (South Central - Berkshire NHS Research Ethics Committee 16/SC/058). The Standards for Universal reporting of patient Decision

This article is protected by copyright. All rights reserved 
Aid Evaluation (SUNDAE) Checklist (Sepucha et al., 2018) and the Enhancing the QUAlity and Transparency Of health Research (EQUATOR) CONSORT checklist (Hopewell et al., 2008) have been used to guide the reporting of this study (See Supplementary File 1). The study took place between April 2016 and June 2017.

\section{Outcome Measures}

Decisional Conflict Scale (10 item, three response categories): This validated scale is designed to evaluate the state of uncertainty about a course of action being taken that is likely to occur when the decision involves trade-offs or potential losses or gains. It comprises four parts: Knowledge, Value Clarity, Support and Certainty and provides sub-scores and a total score (O'Connor 1995). Results from the Decisional Conflict Scale were analysed and presented following guidance in the Decisional Conflict Scale User Manual (O'Connor 1995), providing a Total score and sub-scores for Knowledge, Values, Support and Uncertainty. The scores have a range of 0-100, with scores of lower than 25 being associated with implementing decisions and scores of 37.5 or higher associated with decision delay or implementation delay.

Two study specific questionnaires were used:

- Clarity Questionnaire: A study specific questionnaire to gain user feedback on clarity, terminology, usefulness, usability and acceptability of text and images of the CP-PDA.

- CP-PDA questionnaire: A study specific questionnaire to gain feedback on the CP-PDA, usability, utility, level of information provided and likes and dislikes regarding the intervention was designed.

Both were designed with input from two continence nurse specialists and two expert patients known to the study team to check face and content validity. Relevant descriptive statistics were used to analyse results from quantitative questions, plus content analysis of positive and negative free text comments.

\section{Data Collection}

Phase 1: Evidence and expert opinion

In Phase 1, we undertook a comprehensive scoping review of the literature to address the question, "Which continence products work best for which groups of people and when?" via databases (Medline and CINAHL). Limitations on available literature led to the decision to include relevant grey literature from conference proceedings, clinical guidelines and published expert opinion from

This article is protected by copyright. All rights reserved 
respected sources. Any findings where brands rather than product designs or types were discussed or clear commercial interest was identified were excluded. Limitations in the evidence base (e.g. where there were gaps or where the evidence was dated) were discussed on a one-to-one basis with specialist UK based continence clinicians $(n=5)$; results of these discussions were summarised alongside empirical evidence. A convenience sample of clinical experts known to the study team was used.

\section{Phase 2: Prototype Development}

In Phase 2 we used Phase 1 findings and decision aid guidance to develop a prototype, algorithmic intervention to support continence product decision-making, ready for alpha and beta testing. The prototype CP-PDA was initially paper-based and went through iterations with specialist clinician feedback guiding amendments. Seven continence nurse specialists (five from Phase 1 and two further identified via the study team) provided written feedback on the format and content. All nurses were UK based with substantial specialist continence experience. A health literacy specialist advised on format and language.

\section{Phase 3: Alpha Testing}

Alpha testing of the prototype CP-PDA (comprising instructions, one option-grid and product information sheets) assessed the comprehensibility, usability and acceptability with men experienced in product use post-prostatectomy and known to the research team from previous studies. Using the Clarity Questionnaire, they provided feedback on clarity, terminology, usefulness, usability and acceptability (including images used). Additionally, clinicians who regularly assessed patients for continence products were recruited using a letter of invitation from the research team distributed via email from a local collaborator in two NHS Trusts. Clinicians $(n=11)$ took part in a semi-structured interview, including questions on the usefulness and usability of the CP-PDA in every-day practice.

\section{Phase 4: Beta Testing}

Beta testing to gather 'real-world' product-user experience of using the CP-PDA was undertaken with men post-radical prostatectomy as part of a wider study on continence product provision. All men attending 'Trial Without Catheter' clinics in 4 NHS Acute Trusts following radical prostatectomy were invited to participate by their nurse specialist and were eligible to take part if they had the capacity to provide consent and could speak and read English. This patient group is likely to experience at least transient post-surgery urinary incontinence (Haglind et al., 2015). It was

This article is protected by copyright. All rights reserved 
calculated that a total sample of 45 participants ( 15 in the control arm and 30 in the intervention arms) would be needed to demonstrate the clinically relevant difference (described in the Decisional Conflict Scale Manual, O'Connor 1995, of a score of 37.5 or more associated with decision delay and lower than 25 associated with implementing decisions), with 90\% power and a significance level of 0.05. After providing consent, men were randomised by the research nurse (using sealed brown paper envelopes to conceal allocation) to one of three arms: $\operatorname{Arm} A=$ usual care, $\operatorname{Arms} B$ and $C=$ usual care plus the CP-PDA. Arm C participants additionally received any required products free of charge via the study as part of the wider study. 'Usual care' for continence support varied between sites, but broadly comprised the provision of a small number of pads (around three in total) and advice to purchase more as required. Participants in Arms B or C were advised to use the CP-PDA at home to choose more products if they experienced leakage. After 6 weeks, men in all Arms who had needed to purchase further products were asked to complete the Decisional Conflict Scale (O'Connor 1995) to evaluate the impact of the CP-PDA on the 4 sub-categories with the scale (User Knowledge, Value Clarity, Support and Certainty). The Mann-Whitney U test was used to compare the two groups as scores provided continuous data that were not normally distributed (McKinght \& Najab 2010).

\section{Results}

Phase1: Scoping Review

The principal source of literature was the seminal work from the International Consultation on Incontinence and the International Continence Society (Cottenden et al. 2017). Compiled by a globally representative committee of experts, Chapter 20 - Management using Continence Products provides a systematic extensive review of current empirical and expert knowledge on the relative merits of different continence products. Findings from the literature were categorised by product type and patient characteristics and further supplemented by expert opinion from specialist clinicians $(n=7)$ to address gaps in the literature.

From this review, we identified that CP-PDA should:

- Be gender specific as some products are designed specifically for men or women.

- Take into account four key clinical characteristics where evidence suggests that these influence product efficacy or applicability: i) Dependence on a carer for product changes, ii) ability to stand for product changes, iii) type of leakage (light or heavy urinary with or without faecal) and iv) presence of cognitive impairment.

This article is protected by copyright. All rights reserved 
- Take into account different circumstances or situations where evidence or product type/design indicates that products are likely to perform better or worse e.g. prolonged use.

- Be designed for use by product users, carers or clinicians either independently or in partnership with each other.

- Enable choices to be made in order to acknowledge that product choice is 'preference sensitive' and that two men with similar physical needs might have contrasting preferences for leakage containment.

\section{Phase 2: Development of Prototype}

In common with other decision aids, there was a need to balance the requirement for a comprehensive intervention without over-burdening the user with detail or irrelevant information (Savelberg et al., 2017). This necessitated the development of a two-stage CP-PDA to provide the right level of guidance for individuals. To tailor the CP-PDA to the needs of individual men (and avoid presenting information on unsuitable products), two hierarchical steps addressed consecutive questions: 1) What are the patient's relevant clinical characteristics? 2) What are the patient's circumstances/preferences (e.g. do they require long periods between product changes)? The two stage CP-PDA comprised an algorithm and an option table.

1. An algorithm (Figure 1) was designed to address step 1: What are the patient's relevant clinical characteristics?. Four key characteristics were identified: i) Dependence on a carer for product changes, ii) ability to stand for product changes, iii) type of leakage (light or heavy urinary with or without faecal) and iv) presence of cognitive impairment. The simple algorithm allows users with different clinical characteristics to be assigned to one of 12 option tables (each with different combinations of the four key characteristics). The algorithm was developed through iterative use of simulated patient scenarios and the findings from Phase 1. It was tested using a range of commonly encountered situations or circumstances (patient scenarios) until all combinations of characteristics could be catered for in the least possible number of steps. The algorithm used by a healthcare professional for the paper-based version means that the user only receives information relevant to them. For the on-line version, stage one of the algorithm is addressed through a simple set of questions to move the user to the appropriate options.

2. An option table was developed for each of the 12 algorithm end points. Each Option Table lists possible products along the top with further questions at the left-hand side (example in Figure 2). Each Option Table provides a list of possible products along the top with further questions (tailored to the user characteristics of the option-grid) on leakage and daily activities to help refine the user's choice down the side. A traffic light system with green (recommended for most

This article is protected by copyright. All rights reserved 
people), amber (consider) and red (not recommended for most people) is used to guide users. Each option has an information sheet with the pros and cons of the product. The Option Table and information sheets are combined in a booklet on use. An example of how one man chooses his products is also provided to demonstrate how different products work for different activities (e.g. night or day, home or away).

The CP-PDA was developed and evaluated initially as a paper-based tool (e.g. to be provided as a hard copy to a patient at a clinic) with an on-line version to follow. For users of the paper-based CP-PDA, their healthcare professional guides them with the algorithm to select the appropriate option-grid (Figure 1). For those using the on-line version, the algorithm is presented as a short set of simple questions (e.g. Can you stand to change your pad/product?) which lead to the appropriate options.

\section{Phase 3: Alpha Testing}

Ten experienced product users (all male, with prostate related incontinence) provided written feedback on the eight-page A4 CP-PDA booklet. Comments were summarised using three themes:

1) Content provides a useful level of detail, 2) Presentation was generally good, particularly the use of photographs of 'real' men using the products, with suggestions for use of colour and font were provided and 3) Language was generally clear, but there was variation in opinion on some terminology (e.g. diaper). Clinicians ( $n=11$ ) were recruited from two NHS Trusts and the key relevant themes identified from the semi-structured interviews were: 1) Clear to use, but many patients would need support to use it, 2) Useful as an educational tool for non-specialist clinicians or healthcare assistants, 3) Reminds nurses about the range of products available and stops them having 'tunnel vision and just thinking about pads' and 4) Nothing like it available and generally welcomed the opportunity to increase patient awareness of the range available, even if not all products were available from healthcare providers. Findings were discussed within the research team, with any variation in respondent opinion debated and used to further refine the prototype (Example given in Figure 2).

\section{Phase 4: Beta Testing}

Seventy-seven men were recruited to a trial evaluating the CP-PDA in four NHS trusts when they visited for catheter removal post robotic radical prostatectomy. Twenty-one were randomly assigned to Arm A (usual Care) and $n=56$ to Arm B or C (which included giving patients additional chosen products). After catheter removal, 27 men (five from Arm A and 22 from arms B or C) did

This article is protected by copyright. All rights reserved 
not have urinary leakage and therefore did not need to use the CP-PDA. Thirty-four men who received the CP-PDA and 16 who did not receive the CP-PDA experienced leakage requiring continence products and reported their experiences.

The Decisional Conflict Summary Score comprises four sub-scores (Knowledge, Value Clarity, Support and Certainty). Figure 3 provides a summary of Decisional Conflict Scale scores for men who made product purchasing decisions and did $(n=34)$ or did not $(n=16)$ receive the CP-PDA. The total overall Decisional Conflict Score for men with the CP-PDA (mean score $=8$ ) was significantly lower than for those without (mean score $=37$ ) (possible range $0-100$, with $0=$ no decisional conflict and $100=$ extreme decisional conflict) (from Mann-Whitney $U=79.5$, $z$-score $=-3.99307, p=0.0006$ ). Mean scores in all sub-groups (Knowledge, Value Clarity, Support and Certainty) were better for men with the CP-PDA than those without (Table 1).

\begin{tabular}{|l|l|l|l|}
\hline \multicolumn{2}{|l|}{} & $\begin{array}{l}\text { Without CP-PDA } \\
\text { Mean (S.D). } \\
{[95 \% \mathrm{CI}]}\end{array}$ & $\begin{array}{l}\text { With CP-PDA } \\
\text { Mean (S.D). } \\
{[95 \% \mathrm{Cl}] .}\end{array}$ \\
\hline Sub-scores & Knowledge & $\begin{array}{l}50( \pm 18.4) \\
{[40.98,59.02]}\end{array}$ & $\begin{array}{l}10.78( \pm 6.59) \\
{[8.56,12.99]}\end{array}$ \\
& & $34.37 \pm 17.2$ & $9.55 \pm 5.8$ \\
& Value Clarity & {$[25.95,42.80]$} & {$[7.60,11.50]$} \\
\hline & & $30.21 \pm 14.4$ & $4.41 \pm 4.21$ \\
& & {$[23.15,37.27]$} & {$[2.99,5.82]$} \\
\hline & Support & $29.68 \pm 18$ & $2.94 \pm 4.51$ \\
& & {$[20.86,38.49]$} & {$[1.42,4.46]$} \\
\hline Total Score & & $37.1875 \pm 13.1$ & $7.64 \pm 4.36$ \\
& & {$[30.77,43.61]$} & {$[6.1745,9.10]$} \\
\hline
\end{tabular}

Table 1. Mean, Standard Deviation (SD) and 95\% Confidence Intervals for Decisional Conflict Scale sub-scores and total score ( $0=$ no decisional conflict, $100=$ extremely high decisional conflict $)$

Following testing, final minor revisions were made, and an on-line version is now available at www.continenceproductadvisor.org.

\section{Discussion}

This paper presents the development and alpha and beta testing of the first evidence and expert opinion-based intervention to support continence product choice for men post-prostatectomy.

This article is protected by copyright. All rights reserved 
Evaluation indicates that the CP-PDA is easy to use and that it increases confidence in product knowledge and reduces uncertainty. Compared with usual care, men with the CP-PDA reported significantly reduced decisional conflict, with better knowledge of product choice, greater clarity in their values regarding product choice, feeling better supported and being more certain of their choices. The results showed a clinically relevant difference in total scores ( 8 for men with the CPPDA and 37 for those without) with a score of 37.5 or more associated with decision delay and lower than 25 associated with implementing decisions (O'Connor 1995).

The CP-PDA offers the first evidence-based tool to help men to manage incontinence product choices in the challenging post-operative period, and in the longer term when required; an area where men have previously reported feeling unsupported, anxious and confused (Macaulay, Hislop Lennie, Clark O'Neill, \& Fader M, 2018).

The study incorporated input from experienced 'expert' patients, 'real-world' patients and specialist clinicians. The paper-based format is an algorithm differentiating 12 user groups (for use by clinicians), with 12 associated option-grids to help users to refine their choice between product groups. Product information sheets provide detail on both the benefits and disadvantages for each product group. Each user receives a booklet with the appropriate option-grid and accompanying sheets to support them to combine evidence and expert knowledge, with individual circumstances, values and preferences. The CP-PDA is designed to support decision making for people with:

- Different levels and types of incontinence (both bladder and bowel).

- Different types of functional impairment.

- Varying lifestyles and personal values.

The development of the CP-PDA highlights the complexity of choosing the optimal continence management products caused by the combination of variation in incontinence, other co-morbidities, daily activities and preferences. For example, two men with similar types and levels of urinary leakage could have different needs. The recommended products could vary due to differences in functional ability, for example if one can stand and is independent and the other requires the support of a carer. The design of the CP-PDA allows the user to tailor their choices to meet their specific needs and circumstances and aids decision-making to find "the most appropriate pad for each individual to minimize unfavourable side effects" (Getliffe, Fader, Cottenden, Jamieson, \& Green 2007).

This article is protected by copyright. All rights reserved 
The CP-PDA study was part of a project to improve care for men with prostate-related continence problems and therefore recruited from this population. A parallel set of options grids has been developed for women. There is now considerable scope to further evaluate this intervention for different user populations to assess its applicability, e.g. women, those with dementia, those dependent on carers or with faecal incontinence and users outside of the UK.

This study is limited in several ways. Firstly, there is little published empirical evidence to support the use of different products for different circumstances; therefore, the CP-PDA additionally relies on the expert opinion of continence specialists. Whilst this lacks the robustness of an intervention underpinned solely by empirical studies, the considerable expertise gathered and systematic development process used provides more comprehensive and reliable guidance than that currently available. It additionally highlights the need for more research to evaluate product performance for different user groups and in different circumstances. Secondly, the sample size for evaluation was modest and it is not possible to know whether the men are fully representative of the wider population. Finally, it was not possible to blind participants as to the intervention.

\section{Conclusion}

The CP-PDA is the first comprehensive, evidence-based Patient Decision Aid to help guide clinicians and men post-prostatectomy in continence product choice. Field evaluation demonstrates that the CP-PDA is usable and acceptable and significantly reduces decision-making conflict. Additionally, it improves self-reported knowledge and helps increase users' confidence with their decision-making. Further evaluation is required with different patient groups.

\section{Relevance to Clinical Practice}

Choosing continence products is complex due to the range of products available and the necessity to consider clinical need and individual circumstances. The CP-PDA provides nurses with the first comprehensive, evidence-based intervention to help support men post-prostatectomy with their continence product choices. Compared with usual care, the CP-PDA helps men to feel more knowledgeable on product choice, to have greater clarity in their values regarding product decisionmaking, to feel better supported and more certain of their choices. The online version of the CPPDA is now available via www.continenceproductadvisor.org.

This work was funded by the Movember Foundation in partnership with Prostate Cancer UK as part of True NTH programme.

This article is protected by copyright. All rights reserved 
Figure 1 CP-PDA Algorithm

Figure 2 Example of paper-based CP-PDA

Figure 3 Decisional Conflict Scale Scores

This article is protected by copyright. All rights reserved 


\section{References}

- Albkri, A., Girier, D., Mestre, A., Costa, P., Droupy, S., \& Chevrot, A. (2017). Urinary Incontinence, Patient Satisfaction, and Decisional Regret after Prostate Cancer Treatment: A French National Study. Urol Int, 100(1), 50-56.

- Beeckman, D. (2017). A decade of research on Incontinence-Associated Dermatitis (IAD): Evidence, knowledge gaps and next steps. J Tissue Viability, 26(1), 47-56.

- Braaf, S., Lennox, A., Nunn, A., \& Gabbe, B. (2017). Social activity and relationship changes experienced by people with bowel and bladder dysfunction following spinal cord injury. Spinal Cord. 55(7), 679-686.

- Cottenden, A., Fader, M., Beekman, D., Bliss, D., Buckley, B., Kitson-Reynolds, E., Moore, K., Nishimura, K., Ostaszkiewicz, J., Turner, D., Watson, J., \& Wilde, M. (2017). Management of incontinence using continence products. In P. Abrams, L. Cardozo, A. Wagg \& A. Wein (Eds.) Incontinence. 6th ed. ICI-ICS. International Continence Society, Bristol UK.

- Daugherty, M., Chelluri, R., Bratslavsky, G., \& Byler, T. (2017). Are we underestimating the rates of incontinence after prostate cancer treatment? Results from NHANES. Int Urol Nephrol. 49(10), 1715-1721.

- Elwyn, G., O'Connor, A., Stacey, D., Volk, R., Edwards, A., \& Coulter A. (2016) Developing a quality criteria framework for patient decision aids: online international Delphi consensus process. BMJ. 333(7565), 417.

- Fader, M., Cottenden, A., Getliffe, K., Gage, H., Clarke-O'Neill, S., Jamieson, K., Green, N., Williams, P., Brooks, R., \& Malone-Lee, J. (2008). Absorbent products for urinary/faecal incontinence: a comparative evaluation of key product designs. Health Technol Assess. 12(29), iii-185.

- Foster, C., Calman, L., Richardson, A., Pimperton, H., \& Nash, R. (2018). Improving the lives of people living with and beyond cancer: Generating the evidence needed to inform policy and practice. Journal of Cancer Policy. 15(Part B), 92-95.

- Getliffe, K., Fader, M., Cottenden, A., Jamieson, K., \& Green, N. (2007). Absorbent products for incontinence: 'treatment effects' and impact on quality of life. Journal of Clinical Nursing 16(10):1936-45.

- Grzybowska, M., Wydra, D., \& Smutek, J. (2015). Analysis of the usage of continence pads and help-seeking behavior of women with stress urinary incontinence in Poland. BMC Women's Health. 15, 80

This article is protected by copyright. All rights reserved 
- Haglind, E., Carlsson, S., \& Stranne, J. (2015). Urinary incontinence and erectile dysfunction after robotic versus open radical prostatectomy: a prospective, controlled, nonrandomised trial. Eur Urol. 68, 216-225

- Hislop Lennie, K., Clancy, B., Westbury, J., Okamoto, I., \& Fader M. (2018) Understanding men's experience of urinary incontinence post-prostatectomy. Southampton Medical and Health Research Conference.

- Hopewell, S., Clarke, M., Moher, D., Wager, E., Middleton, P., Altman, D., Schulz, K., the CONSORT Group. (2008) CONSORT for reporting randomised trials in journal and conference abstracts. Lancet. 371(9609):281-283.

- Keighley, M., Perston, Y., Bradshaw, E., Hayes, J., \& Keighley D. (2016). The social, psychological, emotional morbidity and adjustment techniques for women with anal incontinence following Obstetric Anal Sphincter Injury: use of a word picture to identify a hidden syndrome. Webb SBMC Pregnancy Childbirth. 16(1), 275.

- Köhler, N., Friedrich, M., Gansera, L., Holze, S., Thiel, R., Roth, S., Rebmann, U., Stolzenburg, J., Truss, M., Fahlenkamp, D., Scholz, H., \& Brähler, E. (2014) Psychological distress and adjustment to disease in patients before and after radical prostatectomy. Results of a prospective multi-centre study. Eur J Cancer Care (Engl). 23(6):795-802.

- Macaulay, M., Broadbridge, J., Gage, H., Williams, P., Birch, B., Moore, K., Cottenden, A., \& Fader, M. (2015). A trial of devices for urinary incontinence after treatment for prostate cancer. BJU Int. 116(3), 432-42

- Macaulay, M., Hislop Lennie, K., Clark O'Neill, S., \& Fader, M. (2018) Catheters and incontinence after radical prostatectomy: Preparing (but not scaring) men. Urology News. Retrieved from https://www.urologynews.uk.com/media/10756/uroma18catheters-v6.pdf.

- Morrison, A., \& Levy, R. (2006). Fraction of nursing home admissions attributable to urinary incontinence. Value in Health. 9, 272-4.

- Noguchi, N., Chan, L., Cumming, R., Blyth, F., Handelsman, D., Seibel, M., Waite, L., Le Couteur, D., \& Naganathan, V. (2016). Lower Urinary Tract Symptoms and Incident Falls in Community Dwelling Older Men: The Concord Health and Ageing in Men Project. J Urol. 196(6), 1694-1699.

- O'connor, A. (1995). Validation of a Decisional Conflict Scale. Med Decis Making. 15(1), 25-30.

This article is protected by copyright. All rights reserved 
- Santini, S., Andersson, G., \& Lamura, G. (2015) Impact of incontinence on the quality of life of caregivers of older persons with incontinence: A qualitative study in four European countries. Archives of Gerontology \& Geriatrics. 63, 92-101.

- Stacey, D., Légaré, F., Lewis, K., Barry, M., Bennett, C., Eden, K., Holmes-Rovner, M., Llewellyn-Thomas, H., Lyddiatt, A., Thomson, R., \& Trevena, L. (2017). Decision aids for people facing health treatment or screening decisions. Cochrane Database Syst Rev. $12 ; 4, \mathrm{CD} 001431$.

- Savelberg, W., van der Weijden, T., Boersma, L., Smidt, M., Willekens, C., \& Moser, A. (2017) Developing a patient decision aid for the treatment of women with early stage breast cancer: the struggle between simplicity and complexity. BMC Med Inform Decis Mak. 17(1), 112.

- Sepucha, K., Abhyankar, P., Hoffman, A., Bekker, H., LeBlanc, A., Levin, C., Ropka, M., Shaffer, V., Sheridan, S., Stacey, D., Stalmeier, P., Vo, H., Wills, C., \& Thomson, R. (2017). Standards for UNiversal reporting of patient Decision Aid Evaluation studies: the development of SUNDAE Checklist. BMJ Qual Saf. 27(5), 380-388.

- $\quad$ Tyson, M., Andrews, P., Ferrigni, R., Humphreys, M., Parker, A., \& Castle, E. (2016). Radical Prostatectomy Trends in the United States: 1998 to 2011. Mayo Clin Proc. 91(1),10-6.

- World Cancer Resarch Fund. Prostate Cancer Statistics. Retrieved from https://www.wcrf.org/dietandcancer/cancer-trends/prostate-cancer-statistics

This article is protected by copyright. All rights reserved 


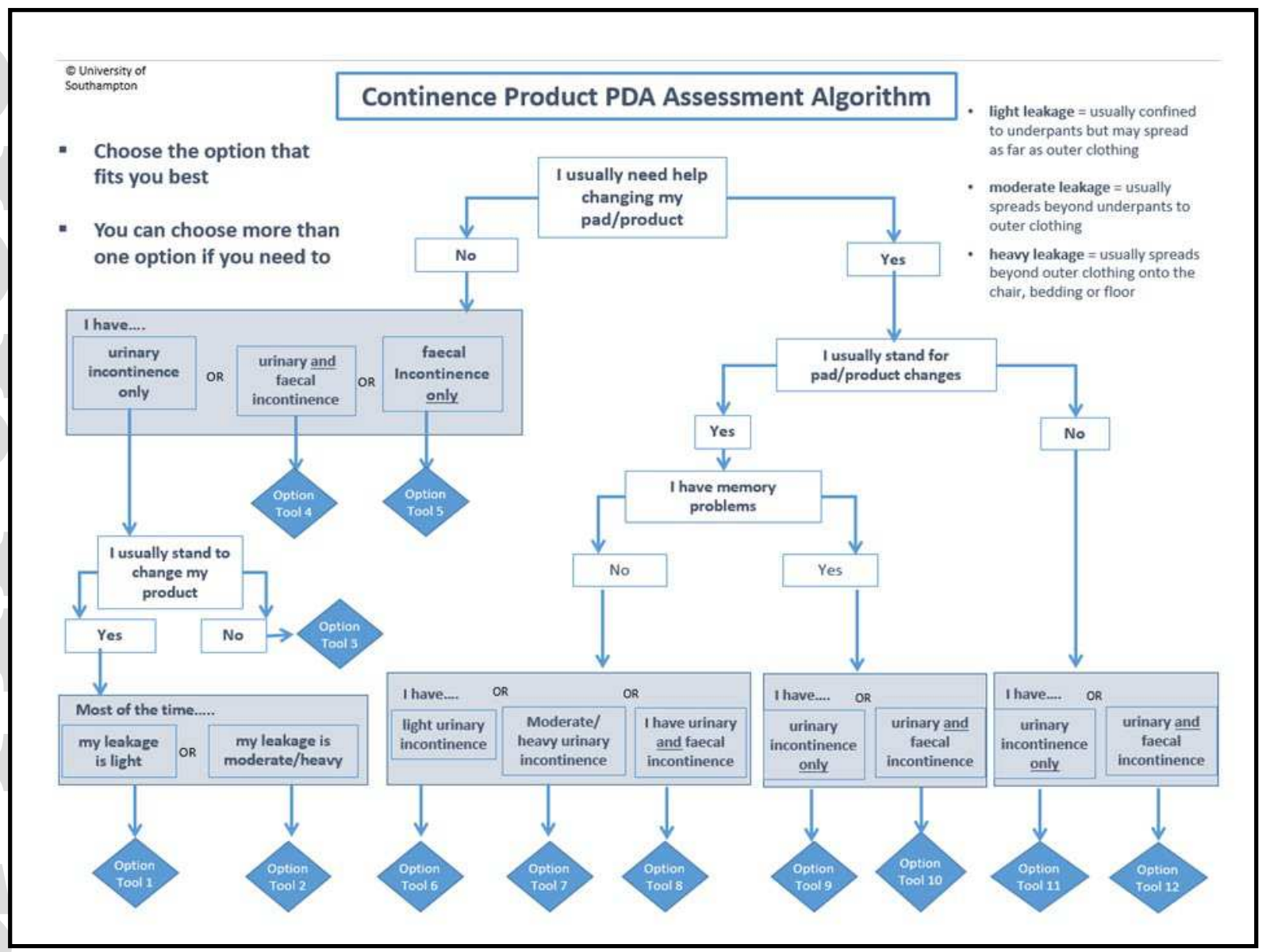

This article is protected by copyright. All rights reserved 


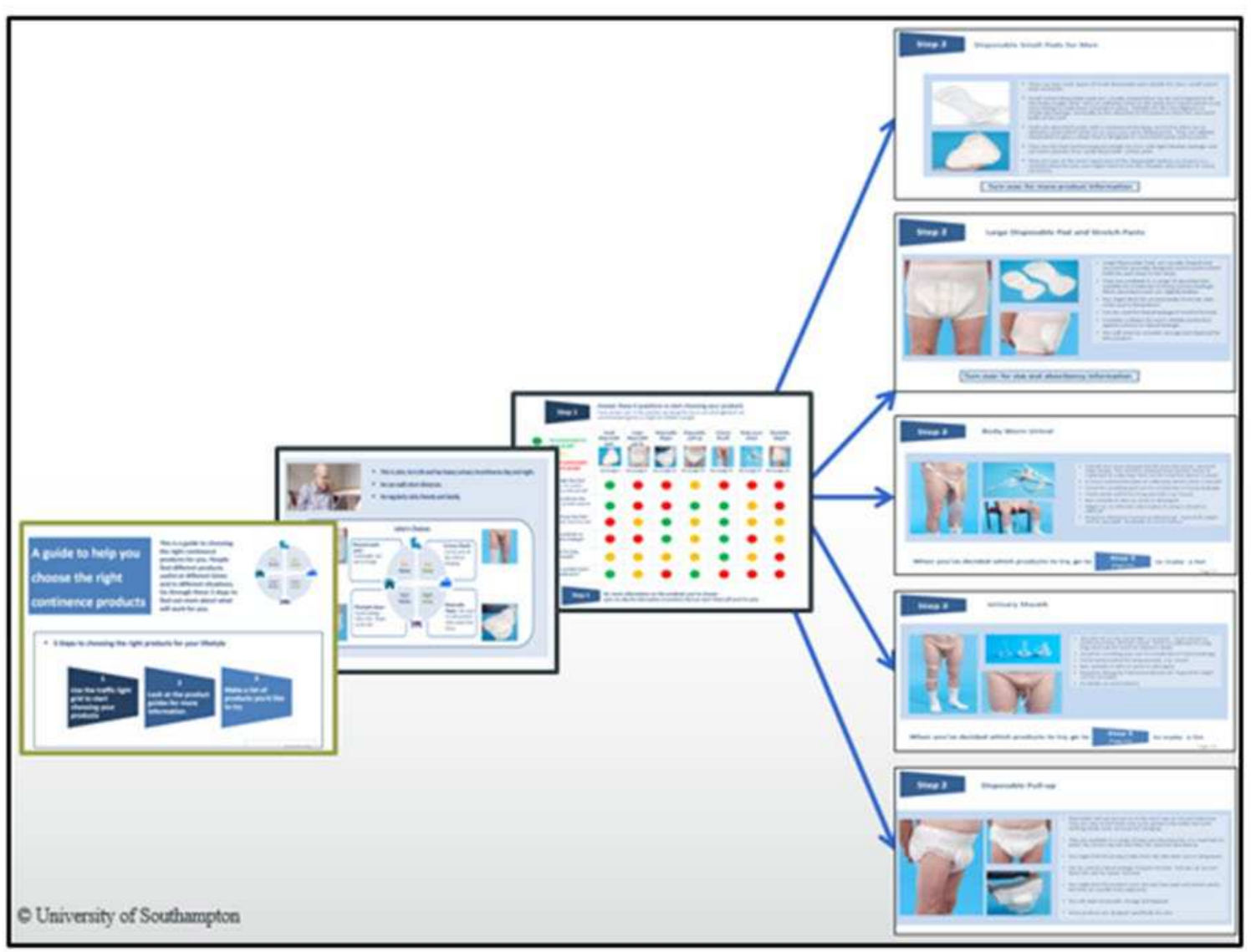

This article is protected by copyright. All rights reserved 


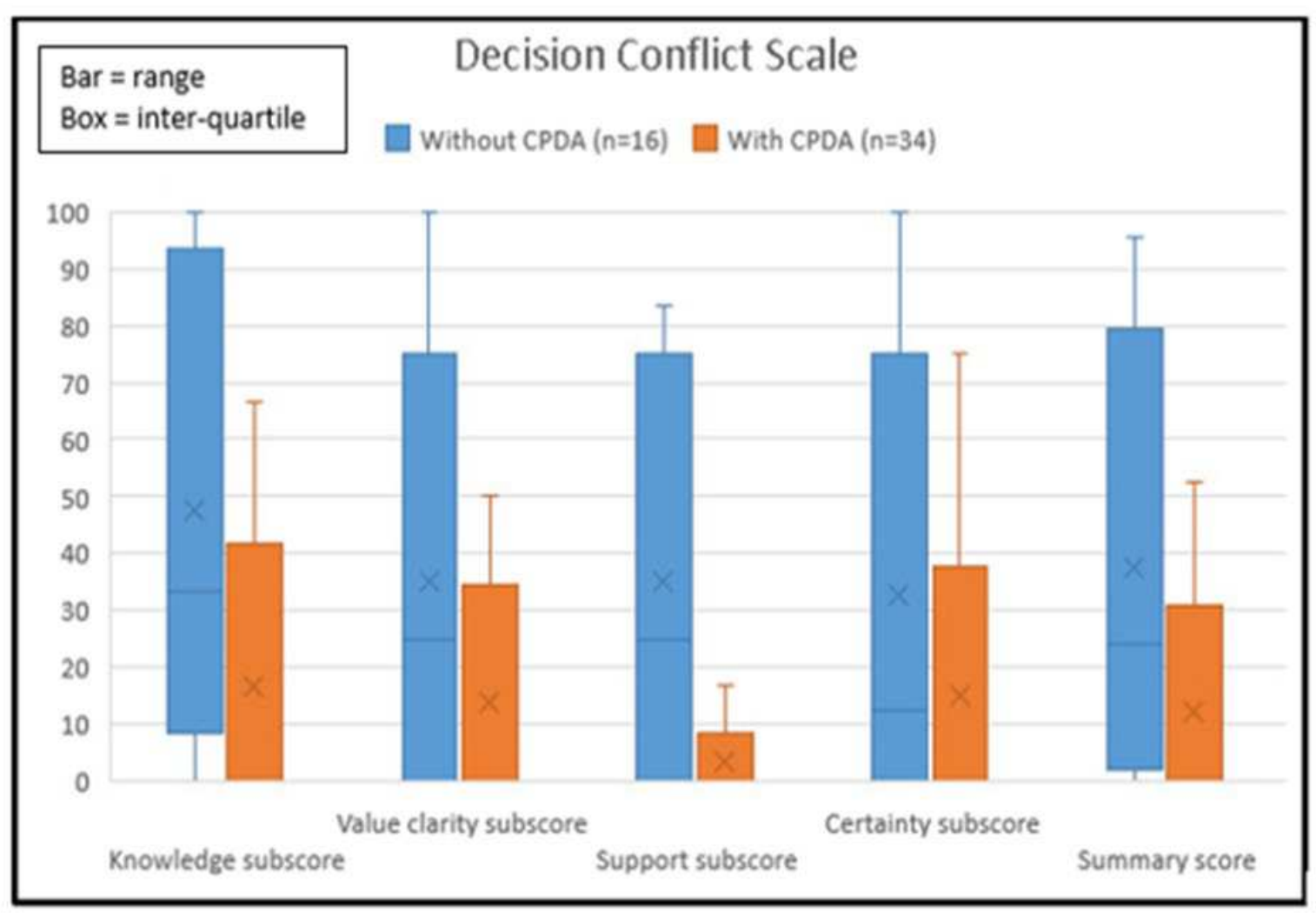

This article is protected by copyright. All rights reserved 